\title{
Shared Agency with Parents for Educational Goals: Ethnic Differences and Implications for College Adjustment
}

\author{
Esther S. Chang • Jutta Heckhausen • \\ Ellen Greenberger $\cdot$ Chuansheng Chen
}

Received: 19 August 2009/ Accepted: 20 November 2009/Published online: 9 December 2009

(C) The Author(s) 2009. This article is published with open access at Springerlink.com

\begin{abstract}
This study proposed and confirmed three ways in which college students can perceive shared agency and two ways in which they can perceive non-shared agency with parents when pursuing educational goals in college. Differences and similarities were examined among participants from four ethnic backgrounds $(N=515 ; 67 \%$ female): East Asian American, Southeast Asian American, Filipino/ Pacific Islander American, and European American. Results indicated that Asian American youth reported higher levels of non-shared agency with parents (i.e., parental directing and noninvolvement), lower levels of shared agency (i.e., parental accommodation, support, or collaboration), and poorer college adjustment compared to European Americans. However, ethnic similarities were found whereby perceived shared agency in education with parents was associated with college adjustment. Multiple mediation analyses also indicated that our model of shared and non-
\end{abstract}

\section{E. S. Chang $(\bowtie)$}

Soka University of America, 1 University Drive,

Aliso Viejo, CA 92656, USA

e-mail: echang@soka.edu

J. Heckhausen · E. Greenberger · C. Chen

Department of Psychology and Social Behavior, University of California, 4201 Social and Behavioral Sciences Gateway, Irvine, CA 92697-7085, USA

J. Heckhausen

e-mail: heckhaus@uci.edu

E. Greenberger

e-mail: egreenbe@uci.edu

C. Chen

e-mail: cschen@uci.edu

C. Chen

Department of Education, University of California,

3200 Education, Irvine, CA 92697-5500, USA shared agency with parents explained differences in college adjustment between Asian and European Americans, though more strongly for comparisons between European and East Asian Americans. Our results suggest that parents continue to be important in the education of older youth but that continued directing of youth's education in college can be maladaptive.

Keywords Late adolescents - Asian Americans . Parenting practices - Parental educational involvement . College adjustment

There is growing recognition in the academic socialization literature that parents are effective when they promote youth's own agency in education (Grolnick and Slowiaczek 1994; Steinberg, Dornbusch et al. 1992; Wang et al. 2007). Yet, research has also shown that parents continue to engage in a variety of practices to maintain their influence on youth (Falbo et al. 2001; Mounts 2002). Though youth and parents often work together on life goals, very few studies have empirically investigated shared pursuit of goals between parent and child, and to the best of our knowledge, no study has focused on the potentially cooperative nature of the parent-child relationship in planning and implementing their youth's educational goals. This study begins to address this gap by investigating youth's perceptions of how parents take part in their education during college. College is an ideal milieu for studying how parents and youth can work together because both independence and connectedness are developmentally appropriate at this time (Steinberg 1990). Since youth are making decisions within an increasingly unpredictable and fast-paced global economy, the successful attainment of educational goals after high school may require more than 
the individual investment of time and effort. Yet, what is the role of parents during the college years and how can parents maintain appropriate involvement?

A recent trend in parenting research has been aimed at identifying the mechanisms and processes through which parenting influences youth's educational achievement, which in turn has led to renewed interest in recognizing the mutuality of influence between parent and child. Relevant to these efforts is the concept of dyadic coping whereby social partners can solve problems jointly with the mutual engagement of each person (Berg et al. 1998). This approach expands upon parenting strategies beyond traditionally studied parenting constructs, such as autonomy support, which refers to how parents support or enable youth to solve problems on their own (Silk et al. 2003). Dyadic coping recognizes that parents have goals for youth and will work with youth in order to attain them. Empirical evidence has thus far found that joint efforts between social partners can maximize health and cognitive outcomes and should not merely be seen as compensating strategies to make up for an individual's lack of ability (Berg et al. 2008; Wiebe et al. 2005). Up until now, dyadic coping within the parent-child relationship has been largely focused on health and particularly on children afflicted with Type I diabetes. This special circumstance may require predetermined health goals and greater "baseline" levels of parental responsibility (Palmer et al. 2009). It is fair to assume that compared to the management of chronic health problems, the selection of postsecondary educational goals and the parents' obligations in ensuring their youth's college success have more variability across families. Therefore, the selection of goals as well as the negotiation between parent and youth about how to pursue them should be addressed in a model of shared agency for educational goals. This is consistent with the fact that motivational theories are highly relevant for understanding academic outcomes as the educational context demands the personal investment of time and commitment (e.g., Eccles 2005).

Of particular importance in models of goal regulation is the notion that individuals implement their goals through a process of goal engagement and disengagement (i.e., Gollwitzer and Bargh 1996; Heckhausen and Heckhausen 2008). Goal engagement involves both behavioral and psychological investment, such as the devotion of time and energy to educational activities, whereas goal disengagement refers to the tendency to reduce efforts or abandon educational goals when over challenged (Haase et al. 2008). Thus, it can be assumed that youth can be either engaged or disengaged with their education at any given time. However, asserting that parents have educational goals for their children (e.g., Hastings and Grusec 1998), it can also be assumed that parents can be goal engaged or disengaged from their offspring's goal pursuit. Subsequently youth and parents can both be goal engaged and disengaged from youth's educational goals. To the extent that youth are goal-engaged and sense that their parents are as well, we propose that youth will perceive shared agency with parents. To the extent that youth are goal disengaged or perceive that their parents are, youth will perceive non-shared agency with parents.

\section{Shared Agency with Parents}

In our conceptualization of shared agency, we differentiate between three different types. All three are related because both youth and parents are interested in pursuing educational goals after high school. Yet, qualitative differences in the inherent goal conflicts between parents and youth make them distinct. Youth may see parents as accommodating to them in the context of differences in parental and youth goals. Alternatively, they may see parents as collaborating through joint efforts to set goals or resolve goal conflicts. A third possibility is that youth may view their parents as relatively "hands-off" while expressing support for their youth's goals. In all three cases, youth recognize parents as active co-managers in youth's education but feel varying degrees of parental influence.

Youth perceive the least amount of parental influence under conditions that reflect parental accommodation, or when their parents are willing to let go and yield to the young person's preferences. Parents who allow youth to exert greater control in their educational pursuits not only display sensitivity and responsiveness to the youth's ability and will but may also help foster youth's own feelings of competence. Parents who are viewed as collaborators retain more influence than accommodators by virtue of their involvement in joint decision-making, discussion, and negotiation. As in dyadic coping, collaborative parents offer potential benefits to youth because youth may view their parents as stakeholders in their future. Both accommodation and collaboration are distinct from parental support. Parents who support adolescents grant them a high degree of autonomy and encourage them to express their individuality-in part because they have demonstrated responsible decision-making in the past (Steinberg, Lamborn et al. 1992). Parental support can be seen as an important element of the authoritative parenting style, which is characterized by autonomy-granting within a climate of warmth and responsiveness. Parental support for education may be conveyed with praise and encouragement when youth make good progress in college and with the provision of emotional and instrumental help when sought by youth. This is conceptually distinct from accommodation because parents who support youth are not letting go of their goals. Given the difficulties of the transition from high school to college and the relative lack of social institutions to guide older youth into adult career entry, 
youth's endorsement of any of the three strategies of shared agency with parents can be expected to be positively associated with indicators of college adjustment.

\section{Non-shared Agency with Parents}

In addition to the three ways in which youth perceive shared agency with parents, either parents or youth can be relatively more goal disengaged. Thus, two patterns of non-shared agency can be distinguished depending upon either youth's own disengagement or the perceived disengagement of their parents. Parents may take over and direct youth's education, akin to the construct of parental behavioral control over younger children, or they may be uninvolved. Traditionally, when parents attempt to control children's behaviors, they monitor them closely and set rules for their activities and parameters for their behavior. In college, youth may feel that their parents are more concerned and invested in their education than they are themselves and may cede decisionmaking "rights" to their parents. Such youth might take the perspective that their parents will guide them in what they think may be best for them. A side benefit is that youth will avoid conflict with parents over the educational path they are pursuing. Parental directing may be an example of "over"involvement, which can be beneficial when considering youth's academic achievement (Wang et al. 2007). However, continued directing may be burdensome due to the negative consequences on their developmental needs for identity and autonomy (Mounts 2002). When parents are perceived to be relatively disengaged from youth's college education, or uninvolved, youth may feel that they are pursuing their educational goals on their own. This may be detrimental due to the lack of felt security with parents while navigating the complex intellectual, social, and identityrelated challenges of the college years (Arnett 2000).

\section{Asian and European American Differences and Similarities}

Decades of research on parenting styles has accumulated evidence that authoritative parenting is optimal for various aspects of youth development with one exception-the case of Asian American adolescents' academic achievement (Dornbusch et al. 1987; Steinberg, Dornbusch et al. 1992). Although Asian American children and younger adolescents routinely report lower levels of parental authoritativeness than do European Americans, they consistently outperform their European American peers academically (Dornbusch et al. 1987). One explanation has been that parental support for youth autonomy is more consistent with the values and prior socialization goals of European than
Asian American families (Chao 1994). Asian traditions rooted in Confucianism specify that the responsibility of parents is to guide and direct their children's education, whereas the child's obligation is to obey and respect their parents' authority (Kim and Choi 1994). In Asian families, educational goals may not be the domain of the individual youth but instead may be interwoven with the family's social status and future well-being (Kagitcibasi 2005).

Still others observe that the Asian American exception points to a larger issue regarding the unsuccessful identification of the processes through which authoritative parenting works, particularly in identifying the goals of both parents and youth in regards to youth's education (Darling and Steinberg 1993). It is possible that Asian American middle and high school youth with parents who direct their education might perform well in school out of family obligations or due to the guidance and assistance parents provide for them. In the developmental context of college, when youth often live away from home or spend less time there, Asian American youth may strive for autonomy due to the greater opportunities for exercising personal choice in college. Despite the better academic performance of Asian American adolescents, they have been found to have lower GPAs relative to their European American counterparts among the handful of investigations involving comparisons of their college achievement (e.g., Dmitrieva et al. 2008; Ying et al. 2001). Dmitrieva et al. (2008) proposed that Asian Americans may experience greater self-regulatory challenges in the transition from high school to college, which is consistent with previous research indicating that Asian families have later timetables for youth autonomy (Feldman and Rosenthal 1991) and higher levels of parentchild conflict than European Americans during the college years (Greenberger and Chen 1996). Thus, continued directing of older youth's education may be difficult or ineffective (Wiebe et al. 2005) and fail to promote academic achievement after high school. Although youth in college are in the transition to adulthood and have greater needs for autonomy than adolescents in middle and high school, they may flounder if parents are uninvolved. Thus, shared agency may be a more productive template for parenting older youth, and our five-factor model may explain some observed ethnic differences in college adjustment.

\section{Research Questions and Hypotheses}

We posed three general research questions within which ethnic differences were examined. The first research question asked how parents are perceived to take part in older youth's college education and whether there are mean level differences between Asian and European Americans in perceived parental participation. It was hypothesized that 
parents can be perceived to be involved in five distinct ways, taking on roles beyond traditionally studied roles for parents in education (i.e., director, supporter, or no role). Based on theories of dyadic coping and goal regulation, we proposed that in addition to parental noninvolvement, directing, and support, youth may perceive parents as collaborators and accommodators. Given these five factors, we expected that Asian Americans would report higher levels of parental directing compared to European Americans who would report higher levels of parental accommodation. These differences were expected to persist after controlling for parental educational attainment, gender, and generational status.

We also asked whether perceptions of shared agency with parents were adaptive for college adjustment and nonshared agency maladaptive across ethnic groups. Due to older youth's developmental needs for greater autonomy and self-regulation after high school, it was expected that perceptions of shared agency with parents would be associated with higher levels of academic adjustment whereas perceptions of non-shared agency, particularly parental directing, would be associated with lower levels of academic adjustment.

Last, if Asian Americans reported lower levels of academic adjustment compared to European Americans, we hypothesized that differences in the proposed five factors of perceived shared and non-shared agency would mediate, or explain, ethnic differences.

\section{Methods}

Procedure and Participants

Participants were 515 undergraduate students (ages 18-25) recruited from a large public university in southern California. Sample recruitment was campus-wide, including announcements in introductory science and math courses for entry into a raffle or extra course credit.

\section{Ethnic Groups}

Asian Americans as a group are culturally diverse and from countries that vary widely in family beliefs and their familiarity with the US. Three distinct groupings of Asian Americans were made based on the differences found in family processes/characteristics (e.g., Blair and Qian 1998; Enrile and Agbayani 2007) and the requirement of adequate cell size for statistical analyses. The Asian American groups were East Asians (e.g., Chinese, Korean, Japanese), Southeast Asians (e.g., Vietnamese, Cambodians, Thais, Laotians), and Filipinos and other Pacific Islanders (e.g., Tongans, Samoans). Forty-four percent of the sample was
East Asian American (EAA, $n=226$ ); $23 \%$ were European American $(n=120), 19 \%$ were Southeast Asian American (SEAA, $n=97$ ), and $14 \%$ were Filipino or Pacific Islander American (FPIA, $n=72$ ). The ethnic diversity of the sample was reflective of the student demographics of the region and university student body. Ethnic groups did not differ in age $(M=19.85$, $S D=1.48)$, academic level ( $29 \%$ freshmen, $25 \%$ sophomores, $25 \%$ juniors, $21 \%$ seniors), and gender (67\% females). However, the distribution of youth's generational status differed when all ethnic groups were compared $\left(\chi^{2}(6, N=514)=320.77, p<.001\right)$. As expected, EuroAmericans were mainly of third generation status or higher $(88 \%)$, whereas less than one-third of students in each Asian group reported that they were third generation $(22 \%$ EAAs, 30\% SEAAs, and 29\% FPIAs). The majority of EAAs (68\%), SEAAs (70\%), and FPIAs (64\%) were second generation and a small proportion of youth within each Asian American group were first generation (10\% EAAs, $0 \%$ SEAAs, and 7\% FPIAs). Ethnic groups differed significantly in parental educational attainment $(F(3,502)=$ 14.01, $p<.001)$ : SEAAs reported significantly lower parental education $(M=2.36 ; S D=1.11)$ than EAAs, FPIAs, and Euro-Americans ( $M \mathrm{~s}(S D \mathrm{~s})=2.90$ (1.03), 3.13 (.68), and 3.18 (.91), respectively; all Bonferroni post hoc comparisons with SEAA had $p \mathrm{~s}<.001)$.

\section{Measures}

\section{Demographic Controls}

In addition to reporting on their gender, students indicated their mother's and father's highest level of educational attainment on a 4-point scale $(1=a$ high school diploma or less; 2 = vocational/technical degree or some college; $3=4$-year college degree; $4=$ master's degree or higher), of which the highest level attained by either parent was used as an indicator of parental educational attainment. Students also supplied information about whether they and their parents were born in the US, which was used to create an indicator of youth's generational status $(1=$ youth and parents were both born outside of US; $2=$ youth was born in the US and parents were born outside of the US; $3=$ youth and parents were both born in US).

\section{Shared and Non-shared Agency with Parents}

Perceptions of parental accommodation, support, collaboration, directing and noninvolvement were measured by the Shared and Non-Shared Agency with Parents in Education scale (SNSA; Chang 2008), which was developed based on focus group interviews of Asian American college students 
and Chinese and Korean immigrant mothers of college students. A pilot test was also conducted to select the best performing set of 3 or 4 items for each subscale. The final scale was 16 items, of which two forms were administered (i.e., 32 items total with 16 regarding perceptions of mother and 16 analogous items regarding perceptions of father) on a 4 -point scale $(1=$ strongly disagree; $4=$ strongly agree). Analogous items for mothers and fathers were averaged as an index of youth's perception of "parents" on a particular item. See Table 1 for item wording.

\section{Adjustment to College}

Three measures were used to indicate students' adjustment to college. The three indicators (described below) were positively intercorrelated, but the size of correlations was small to moderate. Table 2 summarizes descriptive information and intercorrelations among all key study variables.

GPA Academic achievement was measured by one item that asked students to report their college GPA in an openended format. Responses ranged from 1.4 to 4.0 and were normally distributed.

Educational Behaviors Students' personal investment in their academics was measured by 12 items to which participants responded on a 4-point scale $(1=$ never; $4=$ most of the time; Chang 2008). Items were developed to assess behavioral dimensions indicative of academic motivation, such as how often students attend class, take good lecture notes, and keep up with their course readings (overall $\alpha=.72$, ranging from .64 for FPIA to .75 for SEAA).

Educational Satisfaction Students' satisfaction with their educational progress was measured by averaging responses to 8 items (Chang 2008) assessing various aspects of college learning (e.g., "your GPA", "the speed at which you are completing your degree", "the amount of effort you are putting into your classes, "how much you are learning", etc.). Responses were made on a 4-point scale $(1=$ very dissatisfied; $4=$ very satisfied). Overall alpha was .82 , ranging from .80 for each Asian American subgroup to .84 for European Americans.

\section{Results}

How Do Youth Perceive Their Parents To Take Part In Their College Education?

A series of confirmatory factor analyses was conducted on participants' responses to the SNSA scale in order to determine if the proposed five-factor model was the best fit to the observed data. Four competing models, varying from one to four latent variables, of educational goal pursuit with parents were developed and compared using structural equation modeling with AMOS 7.0 in order to examine the extent to which our conceptualization of the five factors were superior to existing models of parental involvement in

Table 1 Factor loadings of the perceived shared and non-shared agency with parents in education scale

\begin{tabular}{|c|c|c|}
\hline Item wording & $b(S E)$ & $\beta$ \\
\hline My mother/father tends to follow my lead when it comes to my education (A) & 1.00 & $.80 * * *$ \\
\hline My mother/father just wants me to be happy in college (A) & $.93(.07)$ & $.71 * * *$ \\
\hline When my mother/father and I disagree about my college plans, s/he always lets me do what I want in the end (A) & $.85(.06)$ & $.66 * * *$ \\
\hline I seek support from my mother/father after making important educational decisions (S) & 1.00 & $.69 * * *$ \\
\hline I turn to my mother/father for comfort when I do not do well on an exam (S) & $1.30(.09)$ & $.74 * * *$ \\
\hline My mother/father is very supportive of how I manage my school activities (S) & $1.09(.08)$ & $.72 * * *$ \\
\hline My mother/father cheers me up when I am having a hard time at school (S) & $1.40(.09)$ & $.84 * * *$ \\
\hline My mother/father will take on my other responsibilities so that I can accomplish my educational goals (C) & 1.00 & $.55 * * *$ \\
\hline If I am busy with school, my mother/father will not tell me about her difficulties and needs (C) & $.67(.09)$ & $.41 * * *$ \\
\hline My mother/father and I tend to negotiate when we disagree on the direction of my college education (C) & $1.04(.11)$ & $.65 * * *$ \\
\hline My mother gives me many suggestions on how I should manage my daily activities in college (D) & 1.00 & $.59 * * *$ \\
\hline My mother/father makes me do what s/he thinks is best for my education (D) & $1.56(.14)$ & $.84 * * *$ \\
\hline My mother/father nags at me if I am not doing what s/he thinks I should be doing at school (D) & $1.38(.12)$ & $.72 * * *$ \\
\hline My mother/father is not responsible for helping me achieve my educational goals (U) & 1.00 & $.70 * * *$ \\
\hline My mother/father does not want to ask me how I am doing in my classes (U) & $.72(.07)$ & $.58 * * *$ \\
\hline I don't need any of my mother/father's help to accomplish my educational goals (U) & $1.24(.10)$ & $.86 * * *$ \\
\hline
\end{tabular}

Latent factors are labeled in the role of parents: $\mathrm{A}=$ accommodate, $\mathrm{S}=$ support, $\mathrm{C}=$ collaborate, $\mathrm{D}=$ direct, $\mathrm{U}=$ uninvolved $* * * p \leq .001$ 
Table 2 Descriptive statistics

\begin{tabular}{|c|c|c|c|c|c|c|c|c|c|c|c|}
\hline & $M(S D)$ & 2 & 3 & 4 & 5 & 6 & 7 & 8 & 9 & 10 & 11 \\
\hline Gender $^{\mathrm{a}}(1)$ & - & .00 & -.08 & -.08 & $-.16^{* * *}$ & $-.09 *$ & .02 & $.18 * * *$ & .07 & -.18 & -.04 \\
\hline Generation (2) & $2.05 \quad(.68)$ & & $.15 * * *$ & $.18 * * *$ & $.19 * * *$ & $-.15 * * *$ & $-.26 * * *$ & $-.11^{*}$ & $.15 * * *$ & $.10^{*}$ & $.25 * * *$ \\
\hline Parent Educ. (3) & $2.90(1.02)$ & & & .06 & $.16^{* * *}$ & .00 & .03 & $-.15 * * *$ & $.24 * * *$ & .08 & $.16^{* * *}$ \\
\hline Accommodate (4) & $2.99 \quad(.59)$ & & & & $.43 * * *$ & $.38 * * *$ & $-.22 * * *$ & -.02 & .08 & .05 & $.29 * * *$ \\
\hline Support (5) & $2.60 \quad(.66)$ & & & & & $.49 * * *$ & .07 & $-.24 * * *$ & $.09 *$ & $.27 * * *$ & $.28 * * *$ \\
\hline Collaborate (6) & $2.62(.58)$ & & & & & & $.24 * * *$ & $-.11^{*}$ & -.04 & $.12 * *$ & .08 \\
\hline Direct (7) & $2.37 \quad(.71)$ & & & & & & & $-.09 *$ & $-.16^{* * *}$ & .05 & $-.22 * * *$ \\
\hline Uninvolved (8) & $1.88 \quad(.62)$ & & & & & & & & -.01 & $-.21 * * *$ & $-.09 *$ \\
\hline GPA (9) & $3.05 \quad(.47)$ & & & & & & & & & $.12 *$ & $.43 * * *$ \\
\hline Educ. behav. (10) & $3.17 \quad(.38)$ & & & & & & & & & & $.26 * * *$ \\
\hline Educ. satis. (11) & $2.78 \quad(.49)$ & & & & & & & & & & \\
\hline
\end{tabular}

$* p \leq .05, * * p \leq .01, * * * p \leq .001$

${ }^{\mathrm{a}}$ Female $=1 ;$ Male $=2$

education. Models were nested and build up to five factors. Model numbers coincide with the number of latent factors (i.e., Model 1 has one latent factor). Comparisons between models were tested by assessing the change in chi-square with the change in the degrees of freedom with the addition of one latent variable. The best-fitting model would have the smallest chi-square value and a significant change in degrees of freedom when compared to the simpler model (Byrne 2001). The Comparative Fit Index (CFI), the Tucker-Lewis non-normed fit index (TLI), and the rootmean-square error of approximation (RMSEA) were used to evaluate model fit because CFI and RMSEA are among the measures least affected by sample size, and TLI penalizes for model complexity (Byrne 2001). By convention, CFI and TLI values greater than .90 are considered indicative of good fit, and RMSEA values less than .08 indicate a reasonable fit and values under .05 indicate a good fit.

Results indicated that Model 1 (all items loaded onto one latent factor of perceived parental involvement in education), Model 2 (items for parental noninvolvement loaded onto one factor and the rest loaded onto a factor of parental involvement), and Model 3 (noninvolvement and directing items loaded onto separate factors and shared agency items loaded onto one factor of parental support) were not a good fit because the chi-square and changes in chi-square were large (e.g., $\chi^{2}=717.02$ for Model 3 and $\Delta \chi^{2}$ from Models 2 to $3=358.92$; all ps $\left.<.001\right)$. Other indices also indicated an insufficient fit (e.g., CFI = .773; $\mathrm{TLI}=.695$; RMSEA $=.11$ for Model 3 ). Model 4 , which distinguished accommodation as a separate factor in addition to three separate factors of noninvolvement, directing, and support (i.e., support and collaboration items) was a reasonable fit to the data, $\chi^{2}(d f=94)=717.02$; CFI $=$ $.876 ;$ TLI $=.827 ;$ RMSEA $=.08$. However, Model 5 which separated out each of the five subscales (i.e., collaboration, accommodation, support, noninvolvement, and directing) improved significantly upon Model $4[\Delta \chi 2$ $(\Delta d f=4)=77.31, p<.001]$. Fit indices for Model 5 were satisfactory and suggested that it was the best-fitting model to the data: CFI $=.903 ;$ TLI $=.859$; $\mathrm{RMSEA}=$ .07 (.06-.08). Mean scores were subsequently calculated for the five subscales and all subscales except collaboration were found to be internally consistent ( $\alpha \mathrm{s}=.77$ accommodation, .83 support, .75 noninvolvement, and .76 directing). The collaboration subscale demonstrated lower reliability, $\alpha=.58$, perhaps because one item tapped into parental intervention (i.e., taking on responsibilities for the benefit of youth's education) whereas another item tapped into parental support (i.e., will not tell youth about difficulties and needs). Descriptive information on all five ways in which parents are perceived to participate in college students' education, as well as their intercorrelations, are included in Table 2. As expected, shared agency subscales (accommodation, support, and collaboration) were positively related to each other and negatively related to noninvolvement; directing was negatively related to accommodation and positively related to collaboration. The positive association between directing and collaboration could be explained by the relatively higher levels of perceived parental engagement in both strategies.

\section{Ethnic Differences}

Asian and European American students were hypothesized to differ in their mean levels of perceived parental participation in their education. Five-one-way analyses of covariance (ANCOVA) tests were conducted separately with each of the five factors as the dependent variable, ethnicity as the grouping variable, and parental educational 
attainment, gender of youth, and youth's generational status as control variables. Ethnic group differences were significant on all five factors: $F \mathrm{~s}(3,484)=3.40, p<.05$ for accommodation; 7.66, $p<.001$ for support; 3.44, $p<.05$ for collaboration, 11.95, $p<.001$ for directing; 4.26, $p<.01$ for noninvolvement (see Fig. 1). As expected all Asian American subgroups reported significantly higher levels of parental directing than European Americans (all Bonferroni post hoc $p s<.05)$. Although means were significantly different across ethnicity, the effect sizes were small. Partial $\eta^{2}$ ranged from .02 (accommodation, collaboration, and noninvolvement) to .07 (directing), meaning that ethnicity accounted for only $2-7 \%$ of the overall variance in each respective strategy. It is also noteworthy that parental accommodation was the most highly endorsed and parental noninvolvement was the least endorsed across ethnicity (see Fig. 1).

Is Shared Agency with Parents Adaptive and Non-Shared Agency Maladaptive?

To assess whether perceived shared agency with parents was adaptive and non-shared agency maladaptive, correlations between the five factors and academic outcomes were conducted. Considering that we were also interested in ethnic comparisons, we conducted our correlations in AMOS 7.0 software in order to take advantage of the multigroup comparison function. Due to limited sample size of ethnic subsamples, we correlated two variables at a time (one of the five factors was correlated with one of the indicators of college adjustment). A total of 15 correlations were tested for significance. The strongest support for our hypothesis was found in the correlations between the five factors of shared and non-shared agency with parents and educational satisfaction. As hypothesized, youths who were more satisfied with their educational progress reported a significantly higher level of perceived shared agency with parents $(r \mathrm{~s}=.28$ for accommodation and support, $p s<.001$, and at trend-level, $r=.08, p=.08$, more collaboration with parents). Also as hypothesized, educational satisfaction was negatively associated with perceived nonshared agency $(r=-.22, p<.001$, for directing and $r=-.09, p<.05$, for noninvolvement). The only correlation with GPA that was significant was perceived parental directing $(r=-.16, p<.001)$, and no correlations with educational behaviors were significant. The size of all significant correlations was small to moderate (Cohen 1988), but the significance of these correlations was not changed when we controlled for parental educational attainment, gender, and generational status.

\section{Ethnic Differences}

We hypothesized that the correlations between the 5 strategies and indicators of college adjustment would be similar across ethnic groups. Each of the 15 correlations (5 strategies correlated with 3 educational outcomes) was tested for equivalence across the four ethnic groups by constraining the correlation to be equal across ethnic groups. The change in Chi-Square (from the baseline model of $\chi^{2}=0$ ) was evaluated against $\Delta d f=3$. Each of the 15 correlations was found to be equal across ethnic groups, which were indicated by a non-significant change in Chi-Square. Thus, older youth across all ethnic groups who perceive their parents as granting greater autonomy

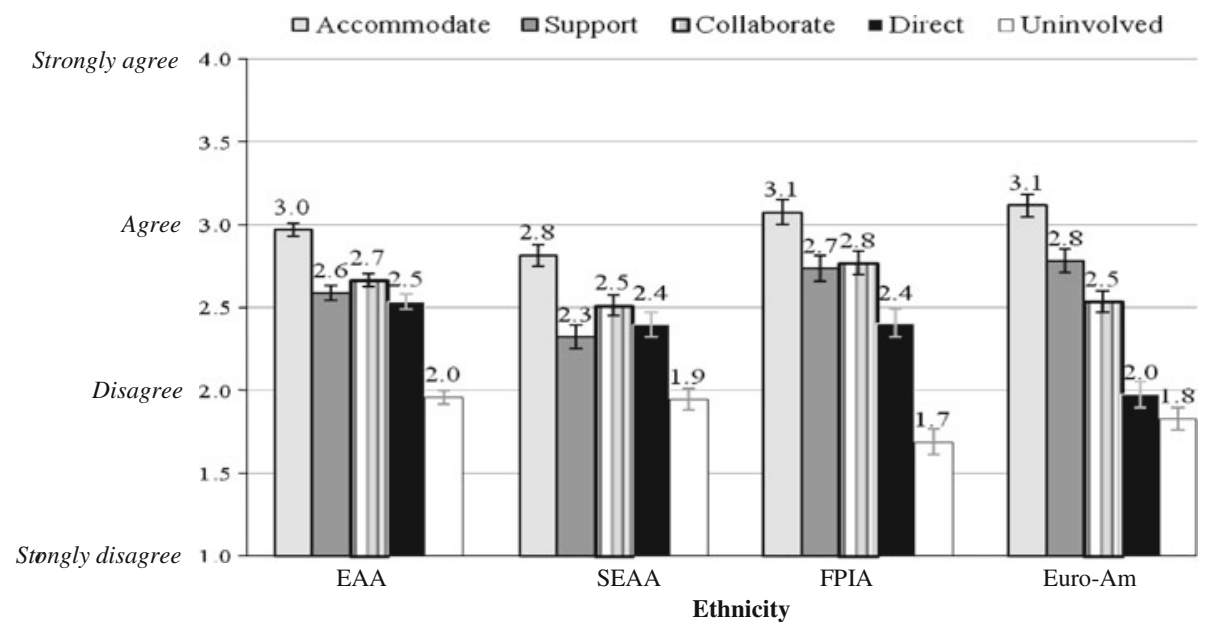

Fig. 1 Mean-level ethnic differences in perceived shared and nonshared agency with parents between East Asian Americans, EAA; $n=218$, Southeast Asian Americans, SEAA; $n=90$, Filipino/ Pacific Islander Americans, FPIA; $n=67$, and European Americans,
Euro-Am; $n=116$. Note: Each of the five factors is labeled to reflect the role of parents. Means are adjusted for parental educational attainment, gender, and youth's generational status and error bars represent standard errors 
and agency in pursuing their educational goals have a more positive adjustment to college.

Does Shared and Non-Shared Agency Mediate

Differences in College Adjustment?

\section{Analysis Plan}

It was hypothesized that if Asian Americans reported lower GPA, educational behaviors, or educational satisfaction compared to Euro-Americans, group differences in perceived shared and non-shared agency with parents would mediate or explain their relatively lower levels of adjustment to college. Since our study involved 5 potential mediators, 3 indices of college adjustment, and 3 Asian American groups to be compared to Euro-Americans, procedures that simplified analyses were preferred over the conventional method of testing a single mediator for each outcome between two ethnic groups at a time (i.e., Baron and Kenny 1986). A series of multiple mediation analyses with bootstrapping (Preacher and Hayes 2008) was conducted because it allowed us to determine the extent to which specific mediators were significant, conditional on the presence of other factors in the model. We requested indirect effects to be calculated by using 5,000 bootstrap re-samples.

Preliminary analyses indicated that 2 out of the 5 strategies (collaboration and noninvolvement) were not significant mediators across all ethnic comparisons and all academic outcomes. These variables were subsequently dropped from further analyses. Perhaps due to the overlap between ethnicity and generational status, generational status was also unrelated to academic outcomes across all ethnic comparisons and was subsequently dropped as a control variable. Our main analyses, reported below, tested a simplified model that included three mediators (i.e., accommodation, support, and directing) and two controls (gender and parental educational attainment) for comparisons between each Asian American group (each was coded 1) with Euro-Americans (coded 0). Differences between an Asian American group and Euro-Americans on the dependent variable were indicated by a significant beta weight for the variable representing the ethnic group comparison. The results are tabled only for educational satisfaction because all three Asian American groups reported lower levels of satisfaction with college compared to Euro-Americans. The results are reported below by each dependent variable.

\section{GPA}

Contrary to patterns found in previous periods of schooling, Euro-Americans reported higher GPAs than EAAs $(b=-.15, S E=.05, p<.01)$ and FPIAs $(b=-.26$, $S E=.07, p<.001)$. No differences in GPA were observed between SEAAs and Euro-Americans. Accordingly, we ran two multiple mediation models to test whether differences in perceived parental accommodation, support, and directing could explain the following group differences in GPA: (1) EAAs compared to Euro-Americans $(n=329)$ and (2) FPIAs compared to Euro-Americans $(n=180)$. Results indicated that the full mediation model with demographic controls accounted for a significant amount of variation in GPA in both group comparisons: Adj. $R^{2} \mathrm{~s}=.09$ for EAAs vs. Euro-Americans and .14 for FPIAs vs. Euro-Americans, $p s<.001$. Consistent with past research, socio-demographic variables were related to college GPA. Students who reported higher parental educational attainment also reported higher GPA in both analyses: $b=.11, S E=.03$, for EAAs vs. Euro-Americans and $b=.15, S E=.04$, for FPIAs vs. Euro- Americans, all $p s<.001$. Only one ethnic group comparison yielded significant gender differences in GPA. In the model with FPIAs and Euro-Americans, males (coded 2) reported lower GPA than females (coded $1, b=.17, S E=.08, p<.05$ ). The three factors as a group (perceived parental accommodation, support, and supervision) were found to be significant mediators of GPA only in the model comparing EAAs and Euro-Americans in GPA $(b=-.07, S E=.06$, $p>.05)$. Bootstrapped confidence intervals also did not contain 0 for the total indirect effect (C.I. $=-.14,-.02$ ) and closer examination of each strategy's significance found that parental directing was a particularly important mediator $(b=-.10, S E=.04, p<.05$; C.I. $=-.12$, $-.01)$. These findings suggest that EAA's higher levels of parental directing explained their lower GPA. Post hoc comparisons of the three strategies in their indirect effects indicated that the contrast between parental directing and accommodation was significant (C.I. $=-.13,-.01$ ), suggesting that both were equally important in explaining differences in GPA between EAAs and Euro-Americans (Preacher and Hayes 2008).

\section{Educational Behaviors}

EAAs and SEAAs reported lower behaviors in their education when compared separately to European Americans: $b=-.12, S E=.04, p<.01$ in analyses comparing EAAs and Euro-Americans $(n=327)$ and $b=-.16, S E=.06$, $p<.01$ in analyses comparing SEAAs and Euro-Americans $(n=200)$. The full multiple mediation model with demographic controls accounted for a significant amount of variation in academic behaviors for both sets of analyses; Adj. $R^{2}=.10$ for EAAs vs. Euro-Americans and .11 for SEAA vs. Euro-Americans; all $p \mathrm{~s}<.001$. Among demographic controls, gender was significantly associated with 
educational behaviors only when EAAs were compared to Euro-Americans. Males in both ethnic groups reported lower levels of motivation during college compared to females $(b=-.12, S E=.04, p<.01)$. After accounting for perceived accommodation, support, and directing, ethnic differences in educational behaviors between EAAs and EuroAmericans were reduced but still significant $(b=-12$, $S E=.05, p<.05)$ and reduced to non-significance between SEAAs and Euro-Americans $(b=-11, S E=.07, p>.05)$. Bootstrapped confidence intervals for the total indirect effect for both ethnic comparisons contained 0 , suggesting that the three strategies as a group did not mediate ethnic differences in educational behaviors. However, the mediation of specific factors was significant given the presence of the other two factors. Perceived parental accommodation and support were significant mediators of ethnic differences between Euro-Americans and EAAs in educational behaviors (C.I.s $=.00, .05$ and $-.07,-.02$, respectively). Post hoc comparisons of the three mediators indicated that accommodation and support were equally significant in explaining differences in educational behaviors between European and EAAs. Ethnic differences between Euro-Americans and SEAAs were also found to be mediated by perceived support (C.I. $=-.17,-.04)$. Thus, Euro-Americans' higher levels of perceived support relative to SEAAs explained their higher levels of educational behaviors.

\section{Educational Satisfaction}

All Asian American subgroups reported lower levels of educational satisfaction when compared separately to EuroAmericans. Results from multiple mediation analyses with educational satisfaction are summarized in Table 3. As can be seen, the total model accounted for a significant amount of variance in satisfaction with education and a total indirect effect was observed for all three ethnic comparisons. College students from families with higher levels of parental educational attainment reported significantly higher levels of satisfaction across all ethnic comparisons. Inspection of bootstrapped confidence intervals indicated that in all three sets of analyses, Asian Americans' lower levels of satisfaction with their education compared to their EuroAmerican counterparts was mediated by their higher levels of parental directing (i.e., confidence intervals for the indirect effect of perceived parental directing did not contain 0 across all ethnic comparisons). When Euro-Americans were compared to EAAs and SEAAs, parental support also mediated differences in satisfaction.

\section{Summary}

Unlike for previous periods of schooling, Asian Americans, especially EAAs, reported poorer adjustment to college when compared to European Americans across all three indicators of college adjustment. Asian Americans' lower levels of parental support and accommodation as well as their higher levels of perceived parental directing explained their relatively lower levels of college adjustment but more consistently for EAAs than for SEAAs or FPIAs and particularly when educational satisfaction was of focus.

\section{Discussion}

Although it is important for parents to support and encourage youth's own agency in education (Grolnick and Slowiaczek 1994; Steinberg, Dornbusch et al. 1992; Wang et al. 2007), very few researchers have studied the possibility that the parent-child relationship can have agency in its own right. Based on the theoretical frameworks of dyadic coping and individual goal regulation, we proposed that this was possible. The results of our study confirm a five-factor model of perceived shared and non-shared agency with parents and the positive associations we found between perceived shared agency with parents and indicators of academic adjustment suggest that parents continue to be important in the education of older youth.

College is often the first step forward in the transition to adulthood and is typically marked by youth having greater freedom and independence from their parents (Arnett, 2000). Yet college youth from all ethnic backgrounds in our study felt that they worked together with parents on their education and within each ethnic group the least endorsed strategy between parents and youth was parental noninvolvement. The relatively high levels of perceived shared agency with parents (accommodation, support, and/ or collaboration) might be a sign that youth are open to their parents' advice, opinions, and cooperation due to the challenges of this important life transition. These findings are also consistent with previous research that has found increases in perceived security with parents during the high-school to college transition compared to other transitions after high school (LaRose and Boivin 1998) and with longitudinal research showing increases in the number of mothers and young-adult children who reported that they felt respect, enjoyment, affection, and understanding with each other (Thornton et al. 1995).

It is noteworthy that parental accommodation was the most highly endorsed form of parental involvement across ethnicity, albeit the least mentioned in the parenting literature. It may be important for future research on parentchild relationships in late adolescence to consider that traditional parenting constructs capture only a limited range of possibilities for parenting during this time. Parents' use of accommodation may be more appropriate for older youth because they are more capable than younger 
Table 3 Mediation of European and Asian American differences in educational satisfaction

\begin{tabular}{|c|c|c|c|c|c|c|}
\hline & \multicolumn{2}{|c|}{$\begin{array}{c}\text { EAA vs. Euro-Am. } \\
n=334\end{array}$} & \multicolumn{2}{|c|}{$\begin{array}{l}\text { SEAA vs. Euro-Am. } \\
\quad n=206\end{array}$} & \multicolumn{2}{|c|}{$\begin{array}{c}\text { FPlA vs. Euro-Am. } \\
n=183\end{array}$} \\
\hline Direct effects & \multicolumn{2}{|c|}{$B(S E)$} & \multicolumn{2}{|c|}{$B(S E)$} & \multicolumn{2}{|c|}{$B(S E)$} \\
\hline Accommodate & \multicolumn{2}{|c|}{$.08 \quad(.05)$} & \multicolumn{2}{|c|}{$.03 \quad(.06)$} & \multicolumn{2}{|c|}{$.11 \quad(.07)$} \\
\hline Support & \multicolumn{2}{|c|}{$.14 * *(.05)$} & \multicolumn{2}{|c|}{$.25 * * *(.06)$} & \multicolumn{2}{|c|}{$.19 * *(.06)$} \\
\hline Direct & \multicolumn{2}{|c|}{$-.13 * *(.04)$} & \multicolumn{2}{|c|}{$-.14 * * \quad(.05)$} & \multicolumn{2}{|c|}{$-.15 * *(.05)$} \\
\hline \multicolumn{7}{|l|}{ Partial effects of controls } \\
\hline Parental ed. attainment & \multicolumn{2}{|c|}{$.05^{*} \quad(.03)$} & \multicolumn{2}{|c|}{$.07 * \quad(.03)$} & \multicolumn{2}{|c|}{$.09 * \quad(.04)$} \\
\hline \multirow[t]{3}{*}{ Gender $^{\mathrm{a}}$} & & & & $(.08)$ & .05 & \\
\hline & \multicolumn{2}{|c|}{ Bootstrapped C.I.'s } & \multicolumn{2}{|c|}{ Bootstrapped C.I.'s } & \multicolumn{2}{|c|}{ Bootstrapped C.I.'s } \\
\hline & Lower & Upper & Lower & Upper & Lower & Upper \\
\hline \multicolumn{7}{|l|}{ Indirect effects } \\
\hline Accommodate & -.04 & .01 & -.07 & .05 & -.07 & .00 \\
\hline Support & -.07 & -.01 & -.24 & -.06 & -.09 & .01 \\
\hline Direct & -.14 & -.03 & -.15 & -.03 & -.16 & -.03 \\
\hline Total & -.21 & -.07 & -.34 & -.13 & -.22 & -.05 \\
\hline Direct vs. accomm & -.14 & -.01 & -.16 & .02 & -.15 & .00 \\
\hline Direct vs. support & -.11 & .01 & -.03 & .17 & -.14 & .01 \\
\hline Accomm vs. support & -.02 & .07 & .00 & .26 & -.03 & .08 \\
\hline Adj. $R^{2}$ & \multicolumn{2}{|c|}{$.13 * * *$} & \multicolumn{2}{|c|}{$.21 * * *$} & \multicolumn{2}{|c|}{$.18 * * *$} \\
\hline
\end{tabular}

EAA $=$ East Asian Americans, SEAA $=$ Southeast Asian Americans, FPIA = Filipino and other Pacific Islander Americans

$* p<.05, * * p<.01, * * * p<.001$

${ }^{\mathrm{a}}$ Female $=1 ;$ Male $=2$

youth in regulating their goals. However, parental accommodation was associated only with youth's satisfaction with their educational progress, i.e., it was not related to GPA or students' behaviors in academics. It is possible that parental accommodation fosters youths' satisfaction with their own education, but due to the cross-sectional nature of our study design, it may be more realistic to say that youth who are satisfied about their college progress are more likely perceive that their parents will follow and accommodate them. Future development of subjective assessments of educational adjustment may be important for evaluating goal progress during college, as opposed to reliance on GPA, as well as longitudinal studies to determine the importance of subjective assessments for career attainment and adult well-being.

The strongest cultural difference we found between Asian and European Americans was in perceived parental directing of educational goals, which is consistent with previous research documenting high levels of parental authority within families of Asian descent (Kim and Choi 1994). However, the across-the-board negative associations between perceived parental directing and college adjustment are also in step with a growing body of literature on culture-general developmental processes (e.g., Wang et al. 2007). These results contribute to deciphering the Asian
American puzzle (Dornbusch et al. 1987). Our findings support the conclusion that authoritative parenting is optimal for all ethnic groups. Previous studies that found ethnic differences in the associations between authoritativeness and achievement during primary and secondary school may, in light of the present findings, reflect ethnic differences in family timetables for youth autonomy. The transition to college may be a time that Asian American youth begin to exercise their autonomy from parents, after which both settle down into a more mutual and egalitarian parentchild relationship. Indeed, college enrollment can represent a fulfillment of youth's family obligations and parents may view their youth more as an adult as a result. On the other hand, our findings may be due to the fact that all participants lived in a Western industrialized nation that values adolescent autonomy and a college context that supports self-determination. A cross-cultural replication of this study in other Asian nations would provide naturallyoccurring quasi-experiments to understand whether parental directing is universally maladaptive during the transition to adulthood. As a limitation of the current study, it should be noted that we relied on youth's self-report to indicate parental directing. Future research should use reports from parents of college students to provide another perspective on whether parental directing is maintained 
during these years and whether ethnic differences in parental directing as well as its maladaptive associations with college adjustment are rooted in youth's perceptions or in actual cultural differences in the parenting of older youth.

The recruitment of students from mathematics, physical and life sciences was an important correction to limitations in past research on college students, which has relied primarily on the participation of students majoring in psychology and/or social sciences. Nonetheless, data was collected from a convenience sample that is not representative of college students in general. Further, this study's needs for large sample size for ethnic group comparisons and for participants who are not used to filling out surveys limited the amount of space available for survey measures. The newly developed scale was brief but operated reasonably well considering its brevity. Future scale development is needed, as well as evidence of its discriminant validity. Despite the limitations mentioned, this is the first research to compare diverse Asian American subgroups with European Americans. Contrary to the assumption that Asian Americans enjoy continued academic success in college, our study suggests that East Asian, Southeast Asian, and Filipino/Pacific Islander Americans may benefit from student services that foster self regulatory skills in higher education (i.e., time management workshops, information about on-campus resources, etc.).

Acknowledgments We acknowledge with gratitude the contributions of Edwin Tan and many undergraduate research assistants for their assistance with data collection. We also thank the School of Social Ecology at the University of California-Irvine for providing funding for this study.

Open Access This article is distributed under the terms of the Creative Commons Attribution Noncommercial License which permits any noncommercial use, distribution, and reproduction in any medium, provided the original author(s) and source are credited.

\section{References}

Arnett, J. J. (2000). Emerging adulthood: A theory of development from the late teens through the twenties. American Psychologist, $55,469-480$.

Baron, R. M., \& Kenny, D. A. (1986). The moderator-mediator variable distinction in social psychological research: Conceptual, strategic and statistical considerations. Journal of Personality and Social Psychology, 51, 1173-1182.

Berg, C. A., Meegan, S. P., \& Deviney, F. P. (1998). A socialcontextual model of coping with everyday problems across the lifespan. International Journal of Behavioral Development, 22, 239-261.

Berg, C. A., Wiebe, D. J., Bloor, L., Butner, J., Bradstreet, C., Upchurch, R., et al. (2008). Collaborative coping and daily mood in couples dealing with prostate cancer. Psychology and Aging, $23,505-516$.
Blair, S., \& Qian, Z. (1998). Family and Asian students' educational performance: A consideration of diversity. Journal of Family Issues, 19, 355-374.

Byrne, B. M. (2001). Structural equation modeling with AMOS: Basic concepts, applications, and programming. Lawrence Erlbaum Associates: Mahwah, New Jersey.

Chang, E. (2008). Ethnic differences and similarities in shared agency between older youth and parents. Doctoral dissertation, University of California, Irvine, 2007. Dissertation abstracts international, 68, (7-B).

Chao, R. K. (1994). Beyond parental control and authoritarian parenting style: Understanding Chinese parenting through the cultural notion of training. Child Development, 65, 1111-1119.

Cohen, J. (1988). Statistical power analysis for the behavioral sciences (2nd ed.). Hillsdale, NJ: Lawrence Earlbaum Associates.

Darling, N., \& Steinberg, L. (1993). Parenting style as context: An integrative model. Psychological Bulletin, 113, 487-496.

Dmitrieva, J., Chen, C., \& Greenberger, E. (2008). Whither the "Whiz Kids" went: Asian American students' transition to college. In G. Li \& L. Wang (Eds.), Model minority myths revisited: An interdisciplinary approach to demystifying Asian American education experiences. Charlotte, NC: Information Age Publishing.

Dornbusch, S. M., Ritter, P. L., Leiderman, P. H., Roberts, D. F., \& Fraleigh, M. J. (1987). The relation of parenting style to adolescent school performance. Child Development, 58, 1244 1257.

Eccles, J. S. (2005). Subjective task value and the Eccles et al. model of achievement related choices. In A. J. Elliot \& C. S. Dweck (Eds.), Handbook of competence and motivation (pp. 105-121). New York: Guilford Press.

Enrile, A., \& Agbayani, P. T. (2007). Differences in attitudes towards women among three groups of Filipinos: Filipinos in the Philippines, Filipino American immigrants and U.S.-born Filipino Americans. Journal of Ethnic \& Cultural Diversity in Social Work, 16, 1-25.

Falbo, T., Lein, L., \& Amador, N. A. (2001). Parental involvement during the transition to high school. Journal of Adolescent Research, 16, 511-529.

Feldman, S. S., \& Rosenthal, D. A. (1991). Age expectation of behavioral autonomy in Hong Kong, Australian and American youth: The influence of family variables and adolescents' values. International Journal of Psychology, 26, 1-23.

Gollwitzer, P. M., \& Bargh, J. A. (1996). The psychology of action: Linking cognition and motivation to behavior. New York: Guillford.

Greenberger, E., \& Chen, C. (1996). Perceived family relationships and depressed mood in early and late adolescence: A comparison of European and Asian Americans. Developmental Psychology, 32, 707-716.

Grolnick, W. S., \& Slowiaczek, M. L. (1994). Parents' involvement in children's schooling: A multidimensional conceptualization and motivational model. Child Development, 65, 237-252.

Haase, C. M., Heckhausen, J., \& Köller, O. (2008). Goal engagement during the school-to-work transition: Beneficial for all, particularly for girls. Journal of Research on Adolescence, 18, 671698.

Hastings, P. D., \& Grusec, J. E. (1998). Parenting goals as organizers of responses to parent-child disagreements. Developmental Psychology, 34, 465-479.

Heckhausen, J., \& Heckhausen, H. (2008). Motivation and action. New York, NJ: Cambridge University Press.

Kagitcibasi, C. (2005). Autonomy and relatedness in cultural context: Implications for self and family. Journal of Cross-Cultural Psychology, 36, 403-422. 
Kim, U., \& Choi, S. H. (1994). Individualism, collectivism, and child development: A Korean perspective. In P. M. Greenfield \& R. R. Cocking (Eds.), Cross-cultural roots of minority child development. Hillsdale, NJ: Lawrence Erlbaum Associates.

Larose, S., \& Boivin, M. (1998). Attachment to parents, social support expectations, and socioemotional adjustment during the high school-college transition. Journal of Research on Adolescence, 8, 1-27.

Mounts, N. (2002). Parental management of adolescent peer relationships in context: The role of parenting style. Journal of Family Psychology, 16, 58-69.

Palmer, K. L., Berg, C. A., Butler, J., Fortenberry, K., Murray, M., Lindsay, R., et al. (2009). Mothers', fathers', and children's perceptions of parental diabetes responsibility in adolescence: Examining the roles of age, pubertal status, and efficacy. Journal of Pediatric Psychology, 34, 195-204.

Preacher, K., \& Hayes, A. (2008). Asymptotic and resampling strategies for assessing and comparing indirect effects in multiple mediator models. Behavior Research Methods, 40, 879-891.

Silk, J. S., Morris, A. S., Kanaya, T., \& Steinberg, L. (2003). Psychological control and autonomy granting: Opposite ends of a continuum or distinct constructs? Journal of Research on Adolescence, 13, 113-128.

Steinberg, L. (1990). Autonomy, conflict, and harmony in the family relationship. In S. S. Feldman \& G. R. Elliot (Eds.), At the threshold: The developing adolescent (pp. 255-276). Cambridge, MA: Harvard University Press.

Steinberg, L., Dornbusch, S. M., \& Brown, B. B. (1992a). Ethnic differences in adolescent achievement. American Psychologist, 47, 723-729.

Steinberg, L., Lamborn, S. D., Dornbusch, S. M., \& Darling, N. (1992b). Impact of parenting practices on adolescent achievement: Authoritative parenting, school involvement, and encouragement to succeed. Child Development, 63, 1266-1281.

Thornton, A., Orbuch, T. L., \& Axinn, W. G. (1995). Parent-child relationships during the transition to adulthood. Journal of Family Issues, 16, 538-564.

Wang, Q., Pomerantz, E. M., \& Chen, H. (2007). The role of parents' control in early adolescents' psychological functioning: A longitudinal investigation in the United States and China. Child Development, 78, 1592-1610.
Wiebe, D. J., Berg, C. A., Korbel, C., Palmer, D. L., Beveridge, R. M., Upchurch, R., et al. (2005). Children's appraisal of maternal involvement in coping with diabetes: Enhancing our understanding of adherence, metabolic control, and quality of life across adolescence. Journal of Pediatric Psychology, 30, 167-178.

Ying, Y., Lee, P. A., Tsai, J. L., Hung, Y., Lin, M., \& Wan, C. T. (2001). Asian American college students as model minorities: An examination of their overall competence. Cultural Diversity \& Ethnic Minority Psychology, 7, 59-74.

\section{Author Biographies}

Esther S. Chang is an Assistant Professor of Psychology at Soka University of America. She received her doctorate in Psychology and Social Behavior from the University of California, Irvine. Her current research interests include cross-cultural and ethnic variations in late adolescent and adult development.

Jutta Heckhausen is a Professor of Psychology and Social Behavior at the University of California-Irvine. She received her doctorate in Psychology from the University of Strathclyde, Glasgow in Great Britain. Her current research focus is on developmental regulation during major life-course transitions, in particular the transition from school to work and to college.

Ellen Greenberger is a Research Professor and Professor Emerita of Psychology and Social Behavior at the University of California, Irvine. She received her doctorate in Clinical Psychology from Harvard University. Her current research interests include crosscultural and ethnic similarities and differences in adolescent and young adult development.

Chuansheng Chen is a Professor of Psychology and Social Behavior and Education at the University of California, Irvine. He received his doctorate in Developmental Psychology from the University of Michigan. His current research interests include cross-cultural adolescent and young adult development and neural bases of learning. 